Research paper

\title{
Thermal analysis of film photovoltaic cell subjected to dual laser beam irradiation
}

\author{
Yu-Chen Yuan, Chen-Wu Wu* \\ Institute of Mechanics, Chinese Academy of Sciences, Beijing 100190, China
}

\section{H I G H L I G H T S}

- Dual laser beam irradiation was utilized to investigate the PV cell responses.

- Temperature dependency of PV cell output voltage was revealed experimentally.

- Iterative algorithm was set up to compute the laser energy deposition in PV cell.

- The PV cell temperature evolution under laser irradiation was obtained by FEA.

- FEA results agreed well with the experimental results for the test point.

\section{A R T I C L E I N F O}

\section{Article history:}

Received 11 June 2014

Received in revised form

19 January 2015

Accepted 20 January 2015

Available online 30 January 2015

Keywords:

Photovoltaic cell

Laser irradiation

Temperature

\begin{abstract}
A B S T R A C T
The concept of dual laser beam irradiation was firstly demonstrated on the photovoltaic cell, of which the temperature dependent efficiency was investigated for wireless power transmission. Then, an analytical model was established to calculate the multiple reflection-absorption of any monochromatic light in multilayer structure, and the heat generation in photovoltaic cell was interpreted. Finally, the finite element analysis was used to simulate the temperature pattern of the photovoltaic cell subjected to laser irradiation. The spatial-temporal characteristic of the temperature field was obtained for improving the system in future.
\end{abstract}

() 2015 Elsevier Ltd. All rights reserved.

\section{Introduction}

The wireless power transmission conducted by some high energy beam is viewed as a promising technology serving for many systems, like Unmanned Aerial Vehicle (UAV). Considering the relative small bulk of the equipment and less energy loss in comparison to other concepts $[1,2]$, the laser-based wireless power transmission technology has already attracted the attention of a great many institutions [3-5]. In fact, this technology also sparkle the great ideas of the space solar power station builders [6,7] because they need to find a way to transport the solar energy collected in space to the ground.

\footnotetext{
* Corresponding author. Institute of Mechanics, Chinese Academy of Sciences, No.15 Beisihuanxi Road, Haidian District, Beijing 100190, China. Tel.: +86 10 82544271.
}

E-mail addresses: chenwuwu@imech.ac.cn, wuchenwu@gmail.com (C.-W. Wu).
The laser-based wireless power transmission equipment mainly consists of two subsystems to convert the electric energy into light energy and then light energy into electric energy. Usually, the electricity-light conversion process is conducted by electropumping laser, while the light-electricity conversion is realized by photovoltaic cell (PV cell). The reduction in weight of the power unit has always been aspired for aircraft and space satellite, therefore the III-V family multilayer thin film PV cells are nowadays widely used in these applications. As we know, such thin film PV cells has the advantages of small size, high efficiency and resistance to radiating degradation, deserving to be an ideal choice for practical applications [8,9].

The overall efficiency of the laser-based wireless power transmission system is determined by the two subsystems, of which only the light-electricity conversion efficiency is involved in this article. It is well known that during photoelectric conversion, the high power density of laser beam would result in significant temperature elevation of the PV cell, which would greatly reduce the 
efficiency of the cell. The main reason is that the temperature elevation would reduce greatly the open-circuit voltage of the cell $[10,11]$ and its fill factor $[12,13]$. In addition, temperature elevation would develop thermal stress in PV cells due to the mismatch in thermal expansion of the materials. The thermal stress would also influence the cell efficiency, as well as cause physical damage in cell and even lead to permanent failure of the cell [14-16]. Therefore, it is very important to comprehend the temperature characteristics of the cell under laser irradiation in order to improve the overall performance of laser-based wireless power transmission system. Moreover, the commonly used multi-junction PV cells always have multiple absorption peaks for the incident laser beams of different wavelengths. Therefore, it is promising to use multiple laser beams to increase the efficiency of the laser-based wireless power transmission system. A typical experiment was developed to investigate the outcome of PV cell subjected to dual laser beams of wavelengths around its absorption peaks [17]. It was revealed preliminarily that the second laser beam did increase the outcome voltage of the PV cell and an obvious inflection point had been observed in the voltage curve, which is believed to be largely dependent on the thermal effect.

This article firstly demonstrates the utilization of dual laser beams of different wavelength, around the double absorption peaks of the thin film PV cell in the light-electricity conversion experiment. Then, the model of multiple reflection-absorption of any monochromatic light in multilayer structure has been established, and the analytic solution of laser energy absorption of each layer in the thin film PV cell has been obtained. Finally, the heat generation in the PV cell during energy conversion is described and the finite element method has been used to simulate the temperature pattern of the PV cell under laser irradiation. The spatial-temporal characteristics of the temperature field are obtained, which is of importance for improving the wireless power transmission system in future.

\section{Experimental description and results}

In the experiment, GaInP/GaAs/Ge three-junction thin film PV cell has been used, of which the absorption peak of GaInP junction and Ge junction appears for the incident light of wavelength about $500 \mathrm{~nm}$ and $1000 \mathrm{~nm}$, respectively. Correspondingly, the two laser beams of wavelengths $532 \mathrm{~nm}$ and $1064 \mathrm{~nm}$ are utilized, in which the maximum output power is about $30 \mathrm{~mW}$ for the shorter wavelength laser and about $25 \mathrm{~W}$ for the longer wavelength laser. Therefore, the higher power laser could be in particular exploited to make a quick temperature ascending circumstance for the thermal effect study. The sketch of the PV cell structure is shown in Fig. 1. Moreover, the PV cell of overall dimensions

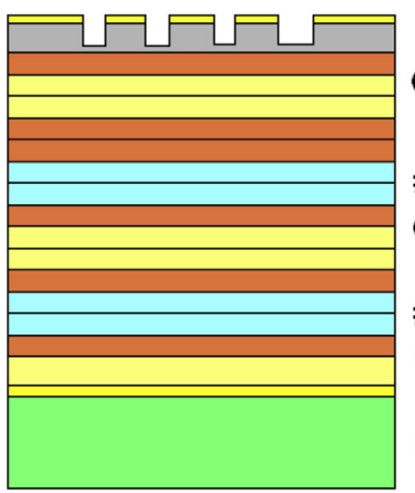

$\mathrm{Ga}_{0.51} \ln _{0.49} \mathrm{P}$ top cell

\#1 tunnel diode

$\mathrm{Ga}_{1-\mathrm{x}} \ln _{\mathrm{x}}$ As middle cell

\section{\#2 tunnel diode}

Ge bottom cell

\section{Ge substrate}

Fig. 1. GaInP/GaAs/Ge photovoltaic cell structure.
$11 \mathrm{~mm} \times 11 \mathrm{~mm} \times 170.184 \mu \mathrm{m}$ is adhered by a $5 \mu \mathrm{m}$ adhesive layer to the aluminum plate of dimensions $50 \mathrm{~mm} \times 35 \mathrm{~mm} \times 1.75 \mathrm{~mm}$.

In structure, the main body of the cell includes the GaInP junction, GaInAs junction, Ge junction and Ge substrate layer. The layer thicknesses of the PV cell are listed in Table 1.

The two laser beams were regulated to irradiate the cell surface almost vertically and fall upon nearly the same spot as shown in Fig. 2, in which the angle between the two beams has been exaggerated for illustration. During test, both the surface temperature at the point $3 \mathrm{~mm}$ away from the center of laser beam covered region and output voltage of the PV cell were continually monitored and recorded. At the beginning of the experiment, the cell was subjected to irradiation by the $532 \mathrm{~nm}$ laser of maximum power $30 \mathrm{~mW}$. When the output voltage was stable, the $1064 \mathrm{~nm}$ laser of maximum power $25 \mathrm{~W}$ was also started to irradiate the cell. After temperature and output voltage have reached some steady values, turn off the $1064 \mathrm{~nm}$ laser and keep on recording the temperature and output voltage till the cell was cooled down naturally. Fig. 3 shows the typical experiment results of voltage output and temperature, respectively. To be noted that the test data are cut at the instant shortly before the action of the large power laser to avoid too much redundancy.

As shown in Fig. 3, the initial voltage (about $1.6 \mathrm{~V}$ ) was generated by the irradiation of $532 \mathrm{~nm}$ laser. After starting the $1064 \mathrm{~nm}$ laser, a temporary increasing appeared in the voltage curve, which means the dual-wavelength laser irradiation could actually improve the total voltage. While the cell voltage decreases sharply with the rapid rising of its temperature after starting the $1064 \mathrm{~nm}$ laser. The cell voltage drops down to zero when the test point temperature reaches about $387 \mathrm{~K}$. It is indicated that such temperature elevation of the cell would inhibit its photoelectric conversion. Later on, the cell experienced a natural cooling procedure and the voltage finally recovered to the initial level after removing the long-wavelength laser. It shows that the decline of the output voltage could be eliminated by decreasing the temperature if the deposited laser energy does not reach the damage threshold of the cell. However, permanent damage would arise if the temperature exceeds critical magnitude [16,17] and the PV cell would fail permanently. Therefore, we need to predict accurately the temperature pattern of the cell under laser irradiation. Moreover, one can see that the test point temperature is almost stable before the action of higher power laser, which means that the heat generation would be accurately predicted theoretically without considering the influence of the lower power laser.

Table 1

Layer thicknesses of the PV cell.

\begin{tabular}{|c|c|c|}
\hline Junction layer & Sub-layer & Thickness \\
\hline \multirow[t]{5}{*}{ GaInP, $1.6 \mu \mathrm{m}$} & AlInP & $0.04 \mu \mathrm{m}$ \\
\hline & n-GalnP & $0.5 \mu \mathrm{m}$ \\
\hline & p-Galn & $1 \mu \mathrm{m}$ \\
\hline & $\mathrm{p}+-$ GaInP & $0.03 \mu \mathrm{m}$ \\
\hline & $\mathrm{p}+$-AlGaInP & $0.03 \mu \mathrm{m}$ \\
\hline \multirow[t]{7}{*}{ GaInAs, $7.584 \mu \mathrm{m}$} & $\mathrm{p}++-\mathrm{AlGaAs}$ & $0.006 \mu \mathrm{m}$ \\
\hline & $\mathrm{n}++-$ GaInAs & $0.006 \mu \mathrm{m}$ \\
\hline & tunneling junction & $0.012 \mu \mathrm{m}$ \\
\hline & $\mathrm{n}+$-AlGaInP/AlInAs & $0.03 \mu \mathrm{m}$ \\
\hline & n-GalnAs & $0.5 \mu \mathrm{m}$ \\
\hline & p-GalnAs & $7 \mu \mathrm{m}$ \\
\hline & $\mathrm{p}+-$ GaInAs & $0.03 \mu \mathrm{m}$ \\
\hline \multirow[t]{5}{*}{ Ge, $21.024 \mu \mathrm{m}$} & $\mathrm{p}++-\mathrm{AlGaAs}$ & $0.006 \mu \mathrm{m}$ \\
\hline & $\mathrm{n}++-$ GaInAs & $0.006 \mu \mathrm{m}$ \\
\hline & tunneling junction & $0.012 \mu \mathrm{m}$ \\
\hline & $\mathrm{n}-\mathrm{Ge}$ & $2 \mu \mathrm{m}$ \\
\hline & $\mathrm{p}-\mathrm{Ge}$ & $19 \mu \mathrm{m}$ \\
\hline Ge substrate, $140 \mu \mathrm{m}$ & & $140 \mu \mathrm{m}$ \\
\hline
\end{tabular}




\begin{tabular}{|c|c|c|}
\hline Junction layer & Sub-layer & Thickness \\
\hline \multirow{5}{*}{$\mathrm{GaInP}, 1.6 \mu \mathrm{m}$} & AlInP & $0.04 \mu \mathrm{m}$ \\
\hline & n-GaInP & $0.5 \mu \mathrm{m}$ \\
\hline & p-GaIn & $1 \mu \mathrm{m}$ \\
\hline & p+-GaInP & $0.03 \mu \mathrm{m}$ \\
\hline & $\mathrm{p}+-\mathrm{AlGaInP}$ & $0.03 \mu \mathrm{m}$ \\
\hline \multirow{7}{*}{ GaInAs, $7.584 \mu \mathrm{m}$} & p++-AlGaAs & $0.006 \mu \mathrm{m}$ \\
\hline & $\mathrm{n}++-\mathrm{GaInAs}$ & $0.006 \mu \mathrm{m}$ \\
\hline & tunneling junction & $0.012 \mu \mathrm{m}$ \\
\hline & n+-AlGaInP/AlInAs & $0.03 \mu \mathrm{m}$ \\
\hline & n-GaInAs & $0.5 \mu \mathrm{m}$ \\
\hline & p-GaInAs & $7 \mu \mathrm{m}$ \\
\hline & p+-GaInAs & $0.03 \mu \mathrm{m}$ \\
\hline \multirow{5}{*}{$\mathrm{Ge}, 21.024 \mu \mathrm{m}$} & p++-AlGaAs & $0.006 \mu \mathrm{m}$ \\
\hline & $\mathrm{n}++-$ GaInAs & $0.006 \mu \mathrm{m}$ \\
\hline & tunneling junction & $0.012 \mu \mathrm{m}$ \\
\hline & $\mathrm{n}-\mathrm{Ge}$ & $2 \mu \mathrm{m}$ \\
\hline & $\mathrm{p}-\mathrm{Ge}$ & $19 \mu \mathrm{m}$ \\
\hline \multicolumn{2}{|c|}{ Ge substrate, $140 \mu \mathrm{m}$} & $140 \mu \mathrm{m}$ \\
\hline
\end{tabular}

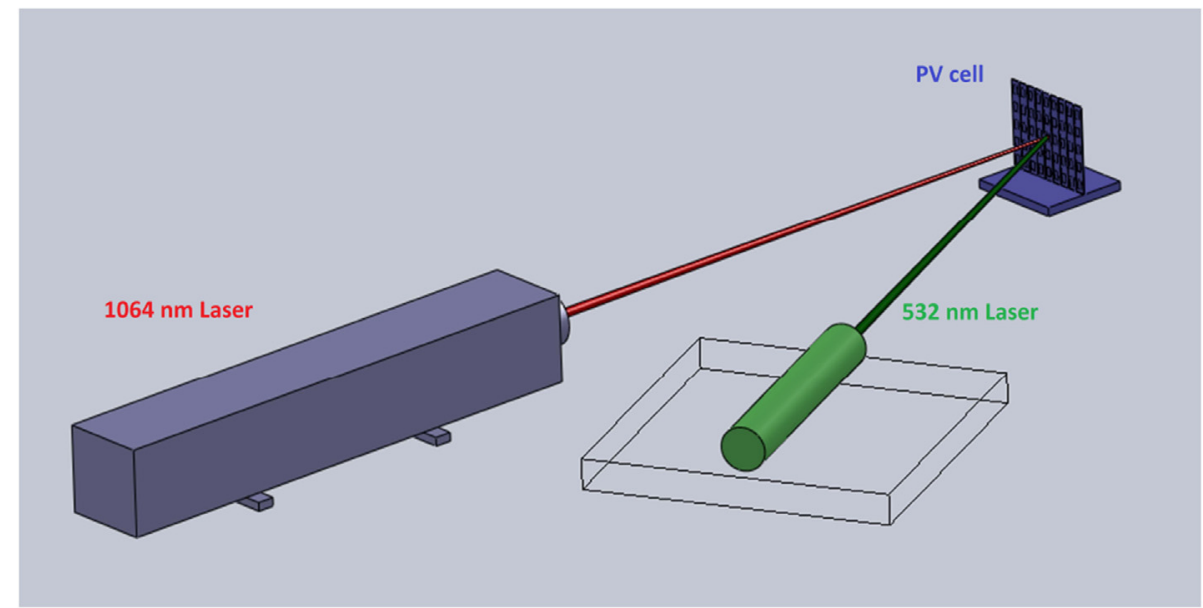

Fig. 2. Diagram of the experimental device.

\section{Light energy absorption in multilayer photovoltaic cell}

As shown in Fig. 1, the main body of the GaInP/GaAs/Ge three junction thin-film PV cell includes four parts: the GaInP junction, the GaAs junction, the Ge junction, and the Ge substrate layer. In each junction, there are p-doped layer, n-doped layer and barrier layer. Between every two adjacent junctions, there is tunnel junction that consisted of two heavily doped layers. And there is also an

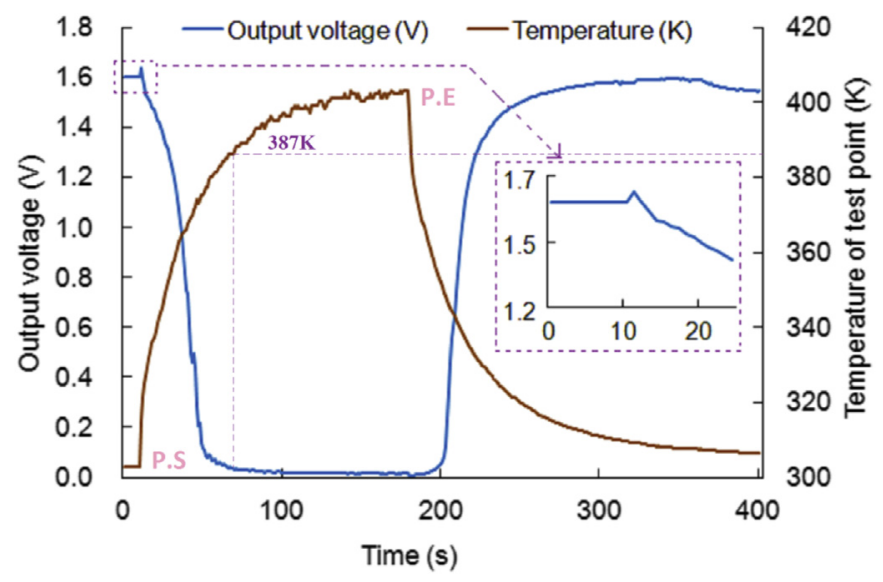

Fig. 3. Voltage fluctuation and temperature history of the photovoltaic cell.
AlInP window layer at the top and a Ge substrate at the bottom of the structure. To establish a mathematic model for thermomechanical analysis of the cell, we need to know the laser energy absorbed by each layer, which depends on the light absorption coefficient of each layer.

The light attenuation in the medium with absorption coefficient $\alpha\left(\mathrm{mm}^{-1}\right)$ obeys the Lambert-Beer Law [18].

$I=I_{0} e^{-\alpha x}$,

where $I_{0}\left(\mathrm{~W} / \mathrm{m}^{2}\right)$ and $I\left(\mathrm{~W} / \mathrm{m}^{2}\right)$ represent the intensity of initially incident light and transmitted light through the medium of thickness $x$, respectively. As the light energy rate is directly proportional to the light intensity, the laser energy absorption after traveling through distance $x$ in the cylindrical domain of unit end-face area could be written as

$E=E_{0}\left(1-e^{-\alpha x}\right)$

where $E_{0}(\mathrm{~W}$, i.e. $\mathrm{J} / \mathrm{s})$ represents the incident laser energy rate, and $E(\mathrm{~W})$ represents the energy rate absorbed by the medium.

As aforementioned, the PV cell used in the experiment is of a multilayer structure. Laser would be reflected at every interface and surface, which makes it more complicated to determine the laser energy deposition in each layer. An iterative algorithm would be established herein to calculate the laser energy deposition distribution in such multilayer medium with considering the multiple 
reflection of laser at the interface and surface. Technically speaking, we should analyze the case for any monolayer as shown in Fig. 4 and then develop a general formula.

In Fig. 4, a monochromic light is assumed to propagate through the monolayer structure and reflect to and fro upon the two boundaries. Wherein $E_{1}$ represents the incident light energy rate through the upper boundary, and $E_{2}$ through the lower boundary. Assume the light energy escaped from the upper surface is $E_{3}$, escaped from the lower surface is $E_{4}$ and the light energy absorbed by the medium is $E_{a}$. Let the reflectivity of the monochromic light upon the upper boundary be $R_{1}$, and that upon the lower boundary be $R_{2}$. Under the present experimental condition, laser beam could be roughly viewed as a normal incidence light, in which the interface reflectivity $R$ between two mediums is [19].

$R=\frac{\left(n_{1}-n_{2}\right)^{2}}{\left(n_{1}+n_{2}\right)^{2}}$.

Wherein, $n_{1}$ and $n_{2}$ represent the refractive indexes of the two mediums separated by the interface, respectively.

Firstly, let's consider the propagation of the incident laser of energy $E_{1}$ through the upper boundary into the monolayer medium. According to the laws of light reflection and absorption, the escaped components $E_{3(1)}, E_{4(1)}$ and absorbed component $E_{a(1)}$ of the incident $E_{1}$ through the upper boundary could be expressed as

$$
\begin{aligned}
E_{3(1)}= & E_{1} \cdot\left[e^{-\alpha d} \cdot R_{2} \cdot e^{-\alpha d} \cdot\left(1-R_{1}\right)\right. \\
& \left.+e^{-\alpha d} \cdot R_{2} \cdot e^{-\alpha d} \cdot R_{1} \cdot e^{-\alpha d} \cdot R_{2} \cdot e^{-\alpha d} \cdot\left(1-R_{1}\right)+\cdots\right]
\end{aligned}
$$

$E_{4(1)}=E_{1} \cdot\left[e^{-\alpha d} \cdot\left(1-R_{2}\right)+e^{-\alpha d} \cdot R_{2} \cdot e^{-\alpha d} \cdot R_{1} \cdot e^{-\alpha d} \cdot\left(1-R_{2}\right)+\cdots\right]$,

and

$$
\begin{aligned}
E_{a(1)}= & E_{1} \cdot\left[\left(1-e^{-\alpha d}\right)+e^{-\alpha d} \cdot R_{2} \cdot\left(1-e^{-\alpha d}\right)\right. \\
& +e^{-\alpha d} \cdot R_{2} \cdot e^{-\alpha d} \cdot R_{1} \cdot\left(1-e^{-\alpha d}\right) \\
& \left.+e^{-\alpha d} \cdot R_{2} \cdot e^{-\alpha d} \cdot R_{1} \cdot e^{-\alpha d} \cdot R_{2} \cdot\left(1-e^{-\alpha d}\right)+\cdots\right] .
\end{aligned}
$$

Theoretically, the light would experience an infinite number of reflections upon the two boundaries of the medium, and there are an infinite number of terms in these expressions. While, one can find out that all of these formulas are actually convergent geometric progressions [20] and can be simplified as

$E_{3(1)}=E_{1} \cdot \frac{R_{2} \cdot\left(1-R_{1}\right) \cdot e^{-2 \alpha d}}{1-R_{1} R_{2} e^{-2 \alpha d}}$,

$E_{4(1)}=E_{1} \cdot \frac{\left(1-R_{2}\right) \cdot e^{-\alpha d}}{1-R_{1} R_{2} e^{-2 \alpha d}}$

and

$E_{a(1)}=E_{1} \cdot \frac{\left(1-e^{-\alpha d}\right)\left(1+R_{2} \cdot e^{-\alpha d}\right)}{1-R_{1} R_{2} e^{-2 \alpha d}}$.

Then, similarly, the escaped components $E_{3(2)}, E_{4(2)}$ and absorbed component $E_{a(2)}$ of the incident $E_{2}$ through the lower boundary can be obtained as

$E_{3(2)}=E_{2} \cdot \frac{\left(1-R_{1}\right) e^{-\alpha d}}{1-R_{1} R_{2} e^{-2 \alpha d}}$

$E_{4(2)}=E_{2} \cdot \frac{R_{1}\left(1-R_{2}\right) e^{-2 \alpha d}}{1-R_{1} R_{2} e^{-2 \alpha d}}$,

and

$E_{a(2)}=E_{2} \cdot \frac{\left(1-e^{-\alpha d}\right)\left(1+R_{1} \cdot e^{-\alpha d}\right)}{1-R_{1} R_{2} e^{-2 \alpha d}}$.

Therefore, the total energy rate absorbed by the medium and escaped through the boundaries can be obtained by adding that resulted from both the incidents $E_{1}$ and $E_{2}$. Let $E_{a 0}$ be the light energy that deposited in medium before the entrance of $E_{1}$ and $E_{2}$, then $E_{a}=E_{a 0}+E_{a(1)}+E_{a(2)}$ and the relationship between $E_{1}, E_{2}$, $E_{a 0}, E_{3}$ and $E_{4}$ could be established in matrix form as

$\left[\begin{array}{lll}E_{1} & E_{2} & E_{a 0}\end{array}\right] \cdot\left[\begin{array}{ccc}T_{11} & T_{12} & T_{13} \\ T_{21} & T_{22} & T_{23} \\ 0 & 0 & 1\end{array}\right]=\left[\begin{array}{lll}E_{3} & E_{4} & E_{\alpha}\end{array}\right]$.

where, $\left[T_{i j}\right]$ is the light transfer matrix with the items of $\left.T_{11}=R_{2} \cdot\left(1-R_{1}\right)\right) \cdot e^{-2 \alpha d} / 1-R_{1} R_{2} e^{-2 \alpha d}$,

$T_{21}=\left(1-R_{2}\right) \cdot e^{-\alpha d} / 1-R_{1} R_{2} e^{-2 \alpha d}$,

$T_{12}=\left(1-R_{1}\right) \cdot e^{-\alpha d} / 1-R_{1} R_{2} e^{-2 \alpha d}$,

$T_{22}=R_{1} \cdot\left(1-R_{2}\right) \cdot e^{-2 \alpha d} / 1-R_{1} R_{2} e^{-2 \alpha d}$,

E3 (light energy escaped from the upper surface)

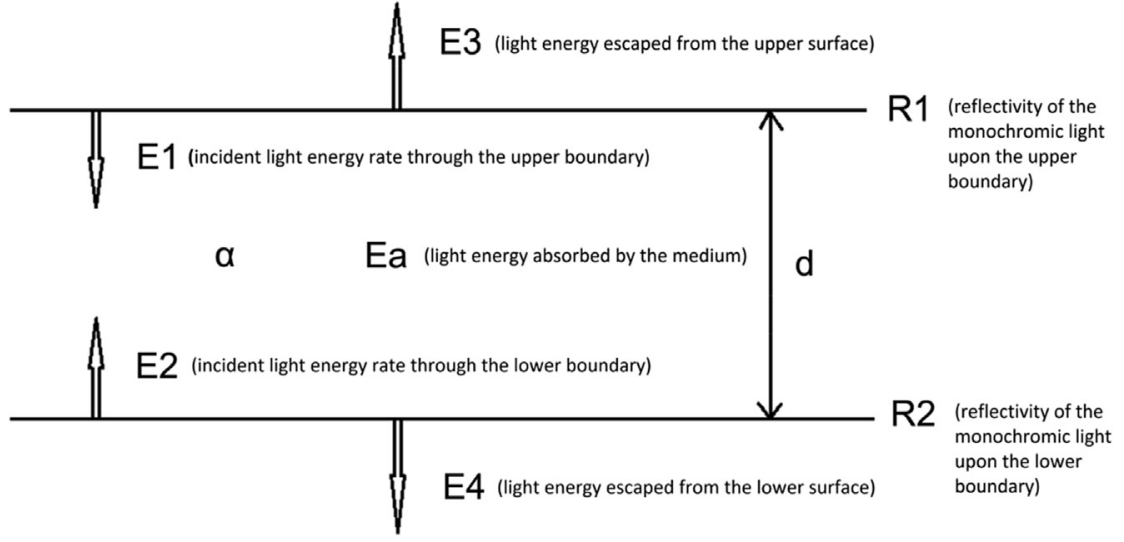

Fig. 4. Diagram of light transfer through any single layer 
$T_{13}=\left(1-e^{-\alpha d}\right)\left(1+R_{2} \cdot e^{-\alpha d}\right) / 1-R_{1} R_{2} e^{-2 \alpha d}$,

$T_{23}=\left(1-e^{-\alpha d}\right)\left(1+R_{1} \cdot e^{-\alpha d}\right) / 1-R_{1} R_{2} e^{-2 \alpha d}$. The matrix in this expression describes the light transmission and absorption in the medium, and can be used directly in the iterative algorithm. It is noteworthy that the heat dissipation is assumed to appear simultaneously considering the fact that the time taken in light propagation through the medium is extreme short in comparison to that for thermal relaxation in the material.

These formulas on monolayer medium can be immediately generalized to multilayer structure as shown in Fig. 5. With every initial and boundary conditions, i.e. the values of $E_{1}, E_{2}$ and $E_{a 0}$ for any certain layer, the $E_{3}, E_{4}$ and $E_{a}$ for that layer can be obtained by Formula (13). Moreover, as depicted in Fig. 5, the escaped energy $E_{3}(2)$ through the upper boundary of the under layer is actually the incident energy $E_{2}(1)$ through the lower boundary of the above layer, which provides the continuous condition on energy flow across every interface. Similarly, the escaped energy $E_{4}(1)$ through the lower boundary of the above layer equals to the incident energy $E_{1}(2)$ through the upper boundary of the under layer. One can also find out that $E_{3}(3)$ is identical to $E_{2}(2)$ and $E_{4}(2)$ is identical to $E_{1}(3)$. To be noted that the sequence number of every layer in Fig. 5 is written in parentheses.

After the initial state, boundary condition and the light transmission matrix are determined, the iterative calculation can be performed and the distribution of light absorption in the multilayer structure can be obtained as demonstrated in Fig. 6. Specifically, at the very beginning of the iterative calculation, $E_{1}$ of the top layer equals to the incident laser energy while other initial incident energy and initially deposited energy are all zero. Then the escaped and absorbed components $E_{3}, E_{4}$ and $E_{a}$ of each layer could be obtained by Eq. (13). If the total subsequent incident energy rate (i.e. the magnitude of $\max \left\{E_{1}(i)+E_{2}(i)\right\}$ ) for any layer is bigger than $1 \mathrm{e}-6 \mathrm{~W}$ (that is, $\mathrm{J} / \mathrm{s}$ ), the iterative continues, and the escaped components $E_{3}, E_{4}$ of every layer are used as the corresponding incident components $E_{1}$ and $E_{2}$ of the adjacent layers in the next round. Once the total subsequent incident energy is not greater than $1 \mathrm{e}-6 \mathrm{~W}$, the iterative calculation would be terminated and the $E_{a}$ of each layer is obtained as the energy absorption in it.

The wavelengths of the two laser beams used in experiment are $532 \mathrm{~nm}$ and $1064 \mathrm{~nm}$, for which the light absorption coefficients, refractive indexes and reflection are generally different. Therefore, the iterative calculation has been performed separately for the two laser beams and the energy deposition in the cell obtained by

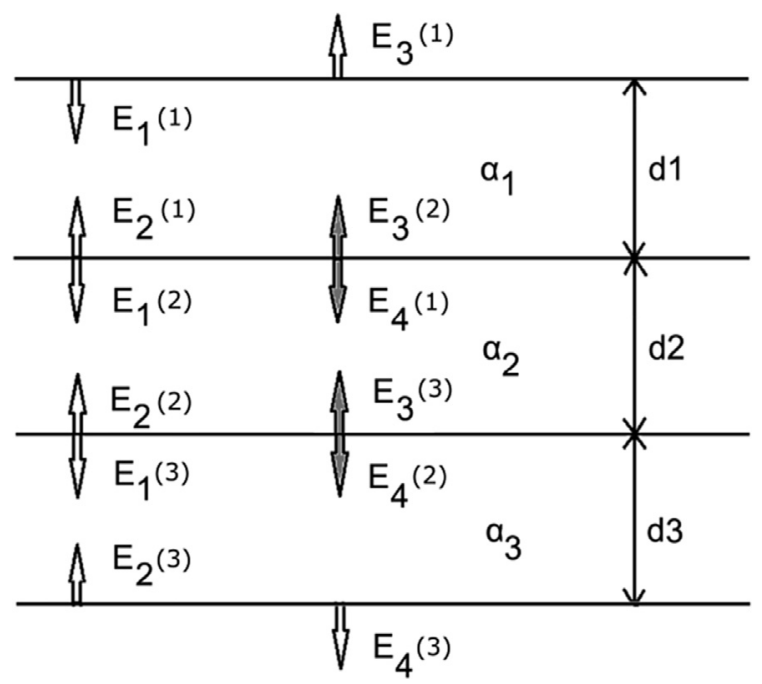

Fig. 5. Model of light reflection, transmission and absorption in multilayer structure.

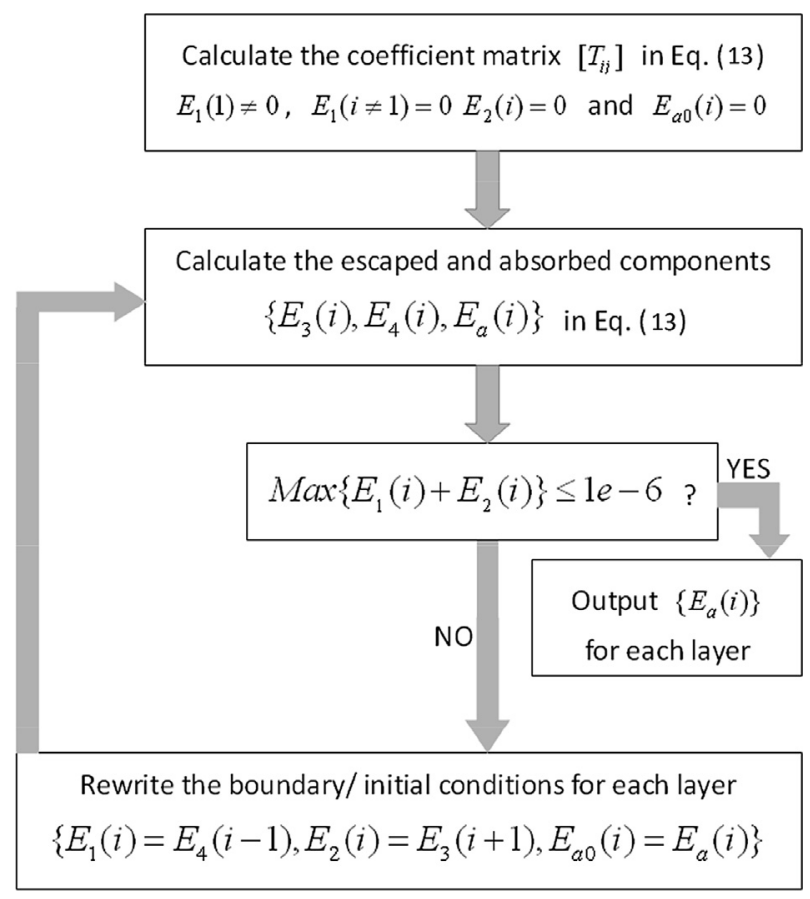

Fig. 6. Diagram of iterative algorithm.

simple addition. Moreover, considering that the cell is irradiated in an open circuit, the light energy absorbed by cell has been assumed to be completely dissipated into heat. Then, the light energy deposition obtained from the above iterative calculation is used as thermal loading conditions in the following finite element analysis.

The rate of light energy deposited in every layer has been calculated for the PV cell subjected to a $25 \mathrm{w}$ laser of wavelength $1064 \mathrm{~nm}$, of which the PV cell material properties are shown in Table 2. As shown in Table 3, the deposited light energy rate in every layer is assumed temporarily confined in a cylindrical domain, of which the end-face area is identical to that of the laser beam covered region.

\section{Finite element analysis on cell temperature}

Although some analytical method could be utilized to solve the heat conduction in a solid subjected to surface heat flux boundary [24], the temperature field of the PV cell under laser irradiation is computed with Finite Element Method considering the complexity in geometry as well as boundary conditions. The quarter finite element model is shown in Fig. 7, in which the cell surface is divided into $20 \times 20$ elements, and each layer of the cell is divided into 5-10 elements along the depth direction. The blank region of the aluminum plate supporting the cell is divided relatively sparse, while fine enough to get convergent solution to the present problem.

Table 2

Main physical parameters of the materials [20-23].

\begin{tabular}{llllll}
\hline & $\mathrm{n}$ & $\alpha / \mu \mathrm{m}^{-1}$ & $\rho / \mathrm{kgm}^{-3}$ & $\mathrm{k} / \mathrm{Wm}^{-1} \mathrm{~K}^{-1}$ & $\mathrm{c} / \mathrm{Jkg}^{-1} \mathrm{~K}^{-1}$ \\
\hline AllnP & 1.843 & 0.100 & 5000 & 8.00 & 400 \\
GalnP & 3.155 & $5.10 \mathrm{E}-5$ & 4470 & 15.75 & 370 \\
AlGalnP & 3.059 & 0.970 & 4890 & 7.50 & 410 \\
AlGaAs & 3.341 & $6.50 \mathrm{E}-5$ & 4850 & 10.89 & 370 \\
GalnAs & 3.615 & 0.280 & 5500 & 5.00 & 300 \\
Ge & 4.409 & 1.40 & 5323 & 58.62 & 310 \\
\hline
\end{tabular}


Table 3

Light energy rate deposited in every layer.

\begin{tabular}{lc}
\hline No. & Energy rate/W \\
\hline Escaped from upper surface & 2.2698 \\
1 & 0.1071 \\
2 & 0.0006 \\
3 & 0.0012 \\
4 & 0 \\
5 & 0.6723 \\
6 & 0 \\
7 & 0.0379 \\
8 & 0.6391 \\
9 & 2.7801 \\
10 & 15.9193 \\
11 & 0.0221 \\
12 & 0 \\
13 & 0.0044 \\
14 & 2.3841 \\
15 & 0.162 \\
Escaped from lower surface & 0 \\
\hline
\end{tabular}

The heat conduction equation of PV cell under laser irradiation can be written as

$\frac{\partial^{2} T}{\partial x^{2}}+\frac{\partial^{2} T}{\partial y^{2}}+\frac{\partial^{2} T}{\partial z^{2}}+\frac{q_{v}}{k}=\frac{\rho c}{k} \frac{\partial T}{\partial t}$

Wherein, the $x, y$ and $z$ represent the Cartesian Coordinates with $z$ along the depth direction as indicated in Fig. 7. $T$ is the temperature and $q_{v}$ is the heat generation rate in specific volume, of which the total light power deposited in every layer is listed in Table 2. Besides, $k$ is the thermal conductivity, $\rho$ material density $\left(\mathrm{kg} \cdot \mathrm{m}^{-3}\right)$, $c$ specific heat $\left(\mathrm{J} \cdot \mathrm{kg}^{-1} \cdot \mathrm{K}^{-1}\right), t$ time $(\mathrm{s})$. The diameter of laser beam used in experiment is about $4 \mathrm{~mm}$ and the laser energy is of Gaussian distribution. Therefore, the internal heat generation region is approximated as a cylinder of average diameter $3 \mathrm{~mm}$ considering again that the light velocity is exaggeratedly larger than the heat diffusion velocity. Thus, the heat generation rate $q_{v}$ in Eq. (14) is assumed to be zero beyond the center cylinder region.

The heat dissipation into the environment through natural convection is treated as the boundary conditions of $k \frac{\partial T}{\partial n}=h\left(T-T_{a}\right)$

where, $n$ is the unit outward vector normal to the surface of the specimen, $T_{a}$ the ambient temperature, $h$ convection coefficient (W m $\left.{ }^{-2} \mathrm{~K}^{-1}\right)$.

Furthermore, the temperature and normal heat flux at each interface within the cell should meet the continuity conditions of

$T^{+}=T^{-}$,

and

$q_{n}^{+}=q_{n}^{-}$.

where the superscripts ' + ' and '-'indicates the two sides across the interface, respectively. The subscript ' $n$ ' represents the unit vector vertical to the interface. Moreover, a relatively low thermal conductivity is applied to the adhesive layer between the cell and aluminum plate to involve the contact thermal resistance effect due to imperfect contact therein.

The total simulation time span is about $390 \mathrm{~s}$ with $170 \mathrm{~s}$ for laser irradiation and $220 \mathrm{~s}$ for solely natural cooling. During the former $170 \mathrm{~s}$, the internal heat generation load and convection boundary condition are applied to the model. In the subsequent $220 \mathrm{~s}$ the internal heat generation load is removed and only the natural cooling process is applied. Specifically, the average ambient temperature is roughly $298 \mathrm{~K}$ during the heating stage and $308 \mathrm{~K}$ during the subsequent cooling stage according to the monitored ambient temperature. The convection coefficient of $65 \mathrm{~W} \mathrm{~m} \mathrm{~W}^{-2} \cdot \mathrm{K}^{-1}$ is used herein. The main physical properties of the materials are listed in Table 1, in which $n$ is the refractive index.

Fig. 8 shows the temperature profiles at the instants of $110 \mathrm{~s}$, $140 \mathrm{~s}, 170 \mathrm{~s}$ and $200 \mathrm{~s}$, in which the maximum temperature appears at instant $170 \mathrm{~s}$ in accordance with the experimental condition and the temperature comes out to be almost even at instant $200 \mathrm{~s}$. The path mapping of temperature at instant $170 \mathrm{~s}$ is shown in Fig. 9. In Fig. 9(a), the paths along $X$ axis starts from the very center of the PV cell and go through its half width. In detail, the curve symbols represent the different locations of the paths with 'top ' being on

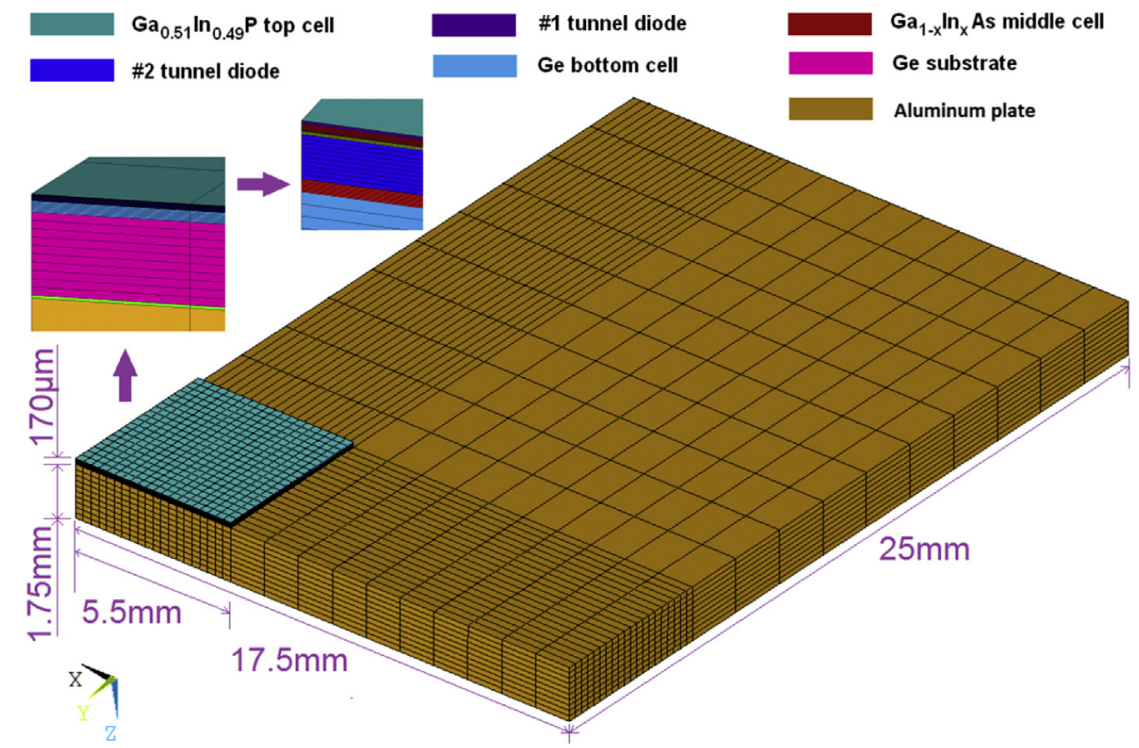

Fig. 7. Finite element meshes of the quarter geometry and partially magnified sketch. 

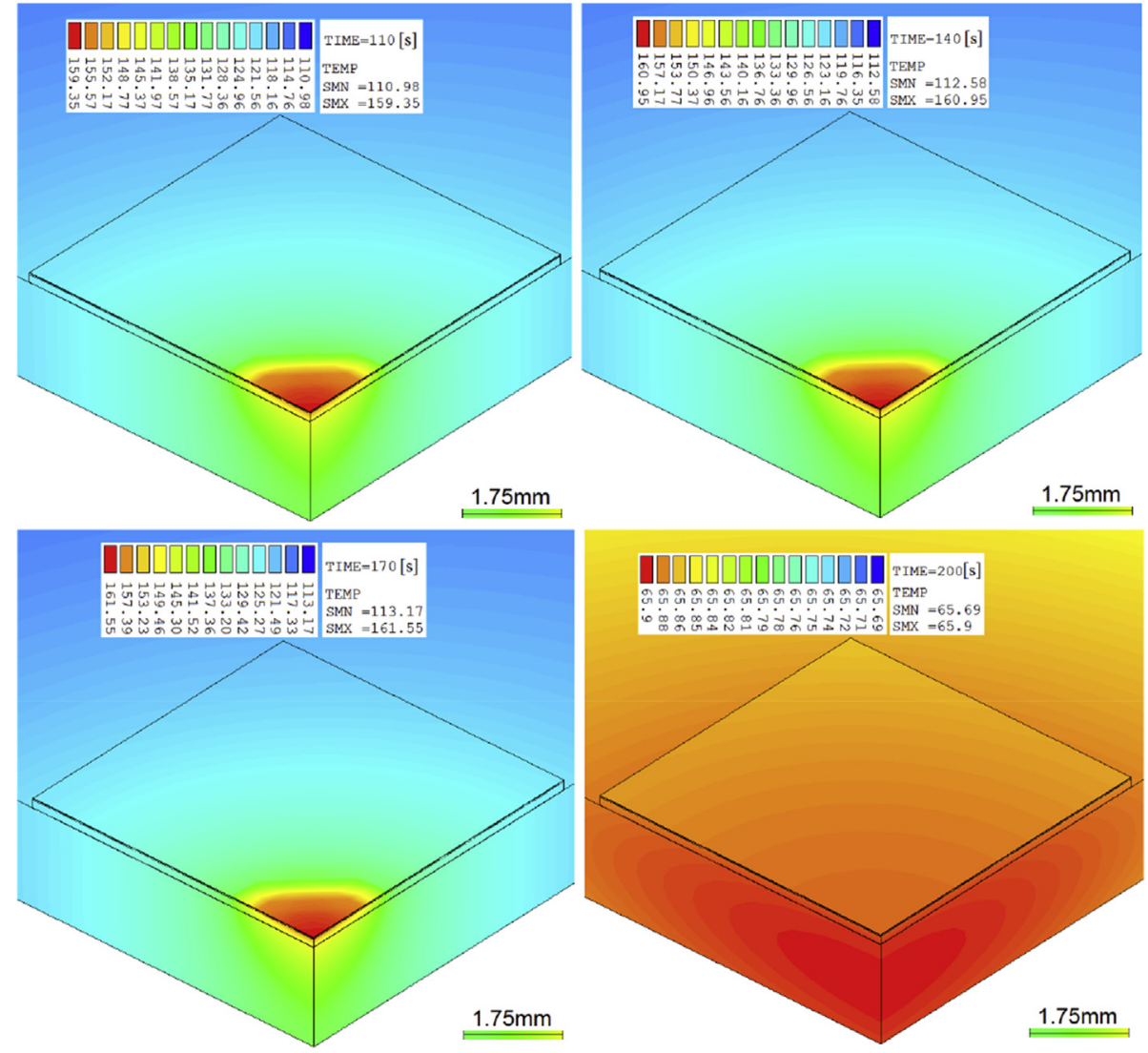

Fig. 8. Temperature $\left({ }^{\circ} \mathrm{C}\right)$ profiles at typical instants for the quarter model.

the surface of cell, 'int1' at the interface between GaInP junction and GaAs junction, 'int2 ' at the interface between GaAs junction and Ge junction, 'int3' at the interface between Ge junction and Ge substrate, 'int_tr' at the interface of cell and adhesive layer and 'tr_bas' at the interface between adhesive layer and aluminum plate. In Fig. 9(b), the path along $\mathrm{Z}$ axis on XOZ plane starts at the center of the surface of cell and ends at the interface between the cell and aluminum plate.

It is shown that the high temperature region is roughly of circular shape, and the maximum temperature at the center of the laser beam covered area is about $440 \mathrm{~K}$. The temperature decreased sharply when getting farther away from the center, especially around the edge of the laser beam covered region. The cell temperature beyond the radiated region is relatively uniform and is about $403 \mathrm{~K}$ in magnitude.

Fig. 9(b) also shows that the peak temperature gradient arises at the adhesion layer between the cell substrate and the supporting plate, which should be owe to the relatively low thermal conductivity of the adhesion layer. Furthermore, it is indicated that the temperature elevation could be reduced by decreasing the thermal resistance of between the PV cell and the supporting plate. For instance, welding might be a choice better adhesive bonding as far as thermal conductivity is taken into account.

To validate the modeling work, the computation temperature results of the point $3 \mathrm{~mm}$ away from the center of laser beam covered region is compared to the experimental results as shown in

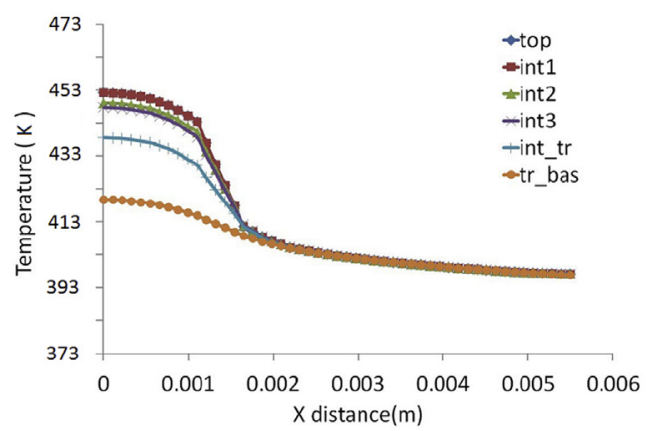

(a)

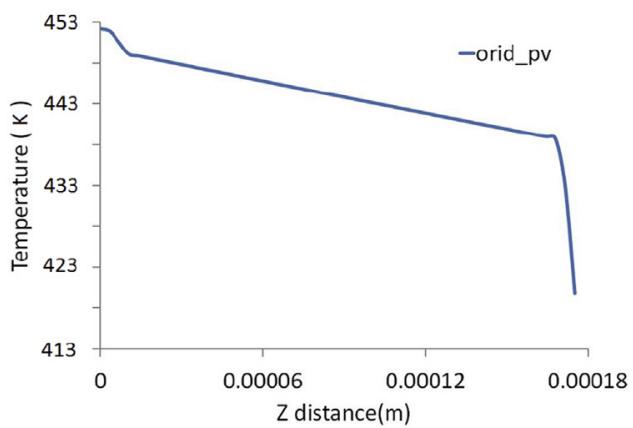

(b)

Fig. 9. Temperature profile at $170 \mathrm{~s}$ mapped onto paths (a) along $X$ and (b) $Z$ axis. 


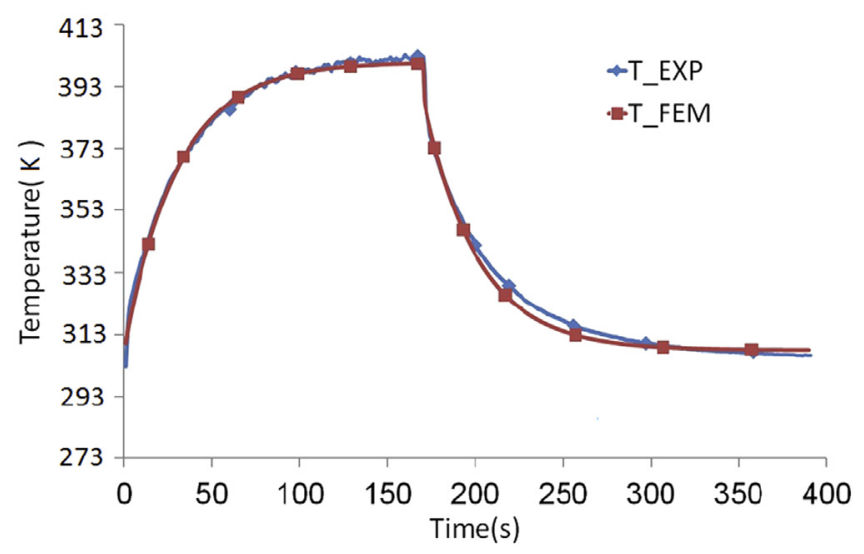

Fig. 10. Computational and experimental temperature history of the test point.

Fig. 10. One can see that the two curves are consistent with both having the peak temperature at the very instant when the high power laser beam was removed. Therefore, one can understand that the present model is trustworthy to provide theoretical prediction on the cell temperature calculation. The rapid decreasing of the temperature indicates that high dynamic thermal stress may arise within the cell, which would lead to the premature failure of the PV cell under irradiation of laser. It is thereby crucial to evaluate the thermo-mechanical reliability of the wireless power transmission system and an upper bound of incident power should be calibrated for that system.

Of course, we could also do some work on thermal management of the PV cell under high power laser irradiation to improve its overall performance. As a matter of fact, the temperature elevation of the PV cell shall be largely reduced by actively cooling the underneath aluminum plate with water flow. Once the temperature of the PV cell could be controlled to low enough, the light-electrical conversion efficient should be maintained high enough and thereby the performance of the wireless power transmission system be improved. The design and optimization of the active cooling of the PV cell and supporting structure shall be focused on in future.

\section{Conclusion}

This article investigated experimentally the responses of a multi-junction film PV cell under dual laser beam irradiation. The results revealed that the cell voltage would be reduced greatly with the cell temperature ascending while be recovered with the cell temperature descending. Moreover, the cell temperature elevation was mainly due to the higher power laser irradiation while as the lower power laser irradiation effect was negligible. An iterative algorithm was established to calculate the light energy deposition in multilayer materials with considering the multiple reflections at the interfaces as well as surfaces. The temperature characteristics of the multi-junction film PV cell under laser beam irradiation were computed with finite element method. Theoretical predicted temperature history of the test point agreed well with the experimental results. The computational results also revealed that the peak temperature gradient arises at the adhesion layer between the cell substrate and the supporting plate, which means that the temperature elevation could be reduced by improve the thermal conductivity of the adhesion layer.

\section{Acknowledgements}

This work was supported by the National Natural Science Foundation of China (Grants No. 11002145 and No. 11332011).

\section{References}

[1] J.T. Howell, M.J. O' Neill, R.L. Fork, Advanced receiver/converter experiments for laser wireless power transmission, in: Proceedings of the 4th International Conference on Solar Power from Space vol. 567, 2004, pp. 187-194.

[2] J.M. Bozek, S.R. Oleson, G.A. Landis, et al., Comparisons of Selected Laser Beam Power Missions to Conventionally Powered Missions, NASA STI/Recon Technical Report N. 94, 1993, pp. 16522-16543.

[3] G.A. Landis, Satellite eclipse power by laser illumination, Acta Astronaut. 25 (1991) 229-233, http://dx.doi.org/10.1016/0094-5765(91)90075-G.

[4] M.D. Williams, R.J. De Young, G.L. Schuster, et al., Power Transmission by Laser Beam from Lunar-synchronous Satellite, National Aeronautics and Space Administration, Washington, D.C, 1993.

[5] C.A. Schafer, D. Gray, Transmission media appropriate laser-microwave solar power satellite system, Acta Astronaut. 79 (2012) 140-156, http://dx.doi.org/ 10.1016/j.actaastro.2012.04.01.

[6] D.M. Flournoy, What is a solar power satellite?, in: J.N. Pelton (Ed.), Solar Power Satellite, Springer, New York, 2012, pp. 1-8.

[7] G.G. Raikunov, V.M. Mel'nikov, A.S. Chebotarev, et al., Orbital solar power stations as a promising way for solving energy and environmental problems, Therm. Eng. 58 (2011) 917-923, http://dx.doi.org/10.1134/ S0040601511110115.

[8] L. Olsen, G. Dunham, D. Huber, et al., GaAs solar cells for laser power beaming, in: Space Photovoltaic Research and Technology Conference, 1991.

[9] R.R. King, D.C. Law, K.M. Edmondson, et al., 40\% efficient metamorphic GaInP/ GaInAs/Ge multijunction solar cells, Appl. Phys. Lett. 90 (2007) 183516, http:// dx.doi.org/10.1063/1.2734507.

[10] M.A. Green, Efficiency limits, losses, and measurement, in: N. Holonyak Jr. (Ed.), Solar Cells: Operating Principles, Technology, and System Applications, University of New South Wales, Sydney, 1998, pp. 85-102.

[11] A. Laudani, F. Mancilla-David, F. Riganti-Fulginei, A. Salvini, Reduced-form of the photovoltaic five-parameter model for efficient computation of parameters, Sol. Energy 97 (2013) 122-127, http://dx.doi.org/10.1016/ j.solener.2013.07.031.

[12] N. Amrizal, D. Chemisana, J.I. Rosell, Hybrid photovoltaic-thermal solar collectors dynamic modeling, Appl. Energy 101 (2013) 797-807, http:// dx.doi.org/10.1016/j.apenergy.2012.08.020.

[13] E. Cuce, P.M. Cuce, T. Bali, An experimental analysis of illumination intensity and temperature dependency of photovoltaic cell parameters, Appl. Energy 111 (2013) 374-382, http://dx.doi.org/10.1016/j.apenergy.2013.05.025.

[14] V.A. Shuvalov, G.S. Kochuojoj, A.E. Prejjmak, Electrical Properties Changes of Solar Panel under Space Environment, vol. 8, Space Science and Technology, 2002, pp. 25-36.

[15] I.Z. Naqavi, B.S. Yilbas, Ovaisullah Khan, Laser heating of multilayer assembly and stress levels: elasto-plastic consideration, Heat Mass Transfer $40(1-2)$ (2003) 25-32, http://dx.doi.org/10.1007/s00231-002-0387-7.

[16] A.V. Kuanr, S.K. Bansal, G.P. Srivastava, Laser-induced damage in InSb at 1.06 pm wavelength- a comparative study with $\mathrm{Ge}, \mathrm{Si}$ and GaAs, Opt. Laser Technol. 28 (1996) 345-353, http://dx.doi.org/10.1016/0030-3992(95) 00115-8.

[17] Y.C. Yuan, C.W. Wu, G.N. Chen, Responses of thin film photovoltaic cell to irradiation under double laser beams of different wavelength, Mater. Sci. Forum 743-744 (2013) 937-942, http://dx.doi.org/10.4028/www.scientific.net/MSF.743-744.937.

[18] J.D. Ingle, S.R. Crouch, Spectrochemical Analysis, Prentice Hall, New Jersey, 1988.

[19] E. Hecht, Optics, fourth ed., Pearson Education, New Jersey, 2008.

[20] A.D. Polyanin, A.V. Manzhirov, Handbook of Mathematics for Engineers and Scientists, Taylor \& Francis Group, LLC, 2007.

[21] S. Adachi, Properties of Semiconductor Alloys: Group-IV, III-V and II-VI Semiconductors, Wiley, New Jersy, 2009.

[22] L. Piskorski, R.P. Sarzała, W. Nakwaski, Self-consistent model of $650 \mathrm{~nm}$ GaInP/ AlGaInP quantum-well vertical-cavity surface-emitting diode lasers, Semicond. Sci. Technol. 22 (2007) 593-600, http://dx.doi.org/10.1088/0268-1242/ 22/6/002.

[23] W.E. Hoke, T.D. Kennedy, A. Torabi, Simultaneous determination of poisson ratio, bulk lattice constant, and composition of ternary compounds: In0.3Ga0.7As, In0.3Al0.7As,In0.7Ga0.3P, and In0.7Al0.3P, Appl. Phys. Lett. 79 (2001) 4160, http://dx.doi.org/10.1063/1.1425954.

[24] P. Majumdar, H. Xia, A Green's function model for the analysis of laser heating of materials, Appl. Math. Model. 31 (2007) 1186-1200. 